\title{
Analysis on the Status and Trend of the Development of China's Pension Industry
}

\author{
Ziyun Ren \\ North China Electric Power University \\ Beijing, China 102206
}

\author{
Chengzhen $\mathrm{Xu}$ \\ North China Electric Power University \\ Beijing, China 102206
}

\begin{abstract}
This article is about the existing problems in the development of China's pension industry and the future trend of the speculation. By selecting the objects of different age groups and using the methods of literature, questionnaires and interviews, the paper analyzes the current situation of aging population, at the same time it discusses the new needs of the aged care industry and contrasts the development model of the elderly care in China and foreign countries so as to promote the continuous improvement of the aged care industry in our country.
\end{abstract}

\section{Keywords—aging; pension industry; development model}

\section{INTRODUCTION}

In recent years, the population of the elderly in our country has rapidly increased, and the trend of aging has obviously worsened. At the same time, with the social problems brought by family planning and the increasing burden on pension funds, the pension industry is facing unprecedented pressure under the new situation. Therefore, focusing on the new needs of the elderly in the pension industry and exploring the appropriate mode of pension development are the top priorities of the reform. It is of great social and economic significance to comprehensively improve the living standard of the elderly, enhance the health quality of the entire people, and promote employment and economic development.

Through the collection of data, questionnaires and field interviews, the paper pays attention to the old people's demands for diverse interests of the aged and combines with the characteristics of the present age to analyze and speculate the existing problems in the process of the development of the aged and provides reference for continuously improving the aged.

\section{CURREnT Situation OF AgING IN ChinA}

According to the statistics of the National Bureau of Statistics of China, the number of elderly people over the age of 60 in China reached 177.6 million in 2010, accounting for $13.26 \%$ of the total population. It is predicted that by 2030 , China's elderly population will reach 248 million, reaching 437 million by 2050 , when the proportion of the elderly population will reach $31.2 \%$ of the total population. As the criterion for judging whether a country enters into an aging society, the United Nations has "10\% of the population over the age of 60 in the total population or $7 \%$ of the population above $65 \% "$. According to this standard, in the late $90 \mathrm{~s}$ China has entered the aging society.

\section{A. China's Aging Characteristics}

The old population has a large base and the number of elderly people over the age of 60 has reached 153 million, which is one fifth of the world's total and also half the population of the elderly in Asia. The elderly population is growing rapidly. By about 2045, the population over the age of 60 in China will account for $30 \%$ of the total population, and the developed countries have spent 100 years. The aging trend is obvious. The population aged over 80 is 13 million, accounting for $9.7 \%$ of the total number of the elderly in the country and an annual increase of about $4.7 \%$ as in "Fig. 1". Since our country entered the ranks of aging countries, the population aging has shown an accelerated trend of development. The aging crisis has become a reality and it has become one of the most important livelihood issues facing our country. 


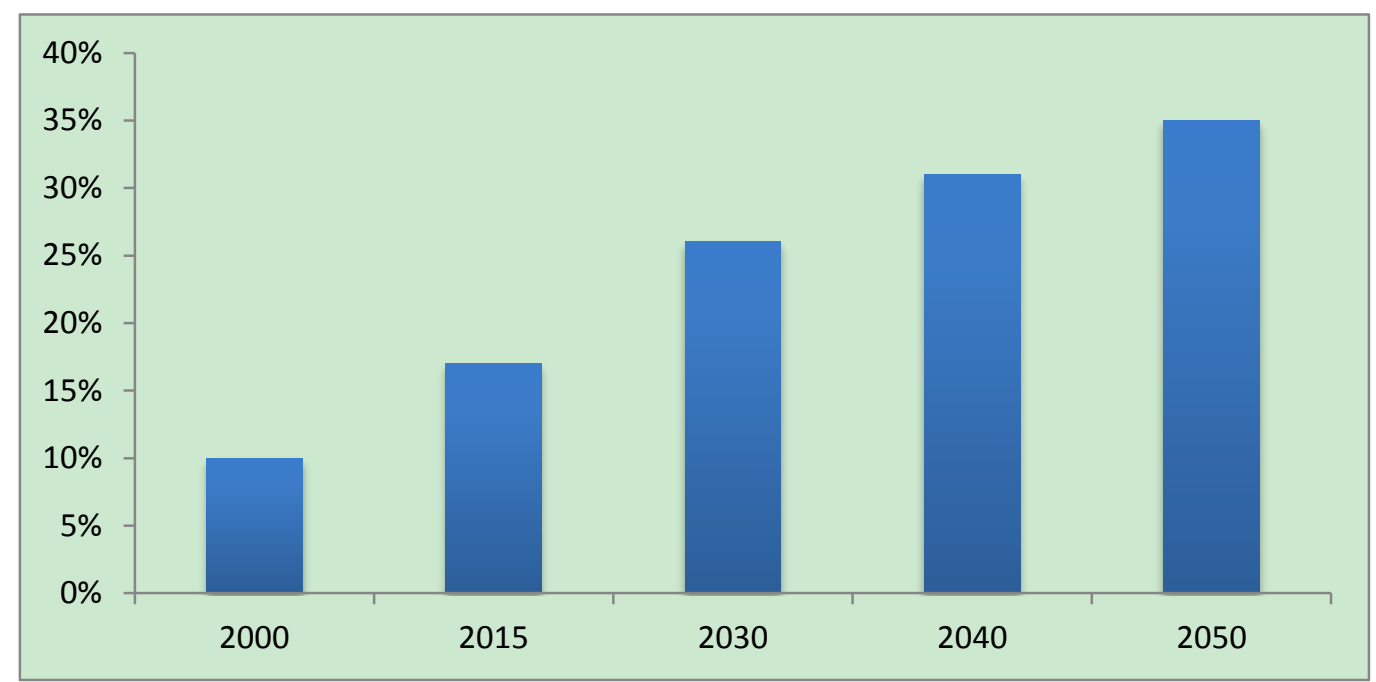

Fig. 1. The proportion of elderly people aged 60 and over.

\section{B. China's Aging Problem}

Under the planned economy, the society did not complete the accumulation of old-age pensions. The "old without getting rich" and the aging of the population did not meet the requirements of social and economic development. Some developed countries in Europe and the United States entered the aging society with per capita GDP is generally between 5,000 and 10,000 U.S. dollars and our country is still under 3,000 U.S. dollars. Therefore China is a typical country of old without getting rich. The family burden on the elderly, the decline in the fertility rate and the prolonged average life expectancy directly lead to the reduction of family support resources and the average per capita burden of supporting children Doubling the growth of old-age care and the actual needs do not match the traditional Chinese culture decided to simply enter the nursing home pension cannot meet the realistic pension needs. Based on this grim reality, pension services are increasingly heavy both for families and for the government as in "Fig. 2". Thus, it is necessary to elevate the pension service industry to a new type of pension industry supported by the state.

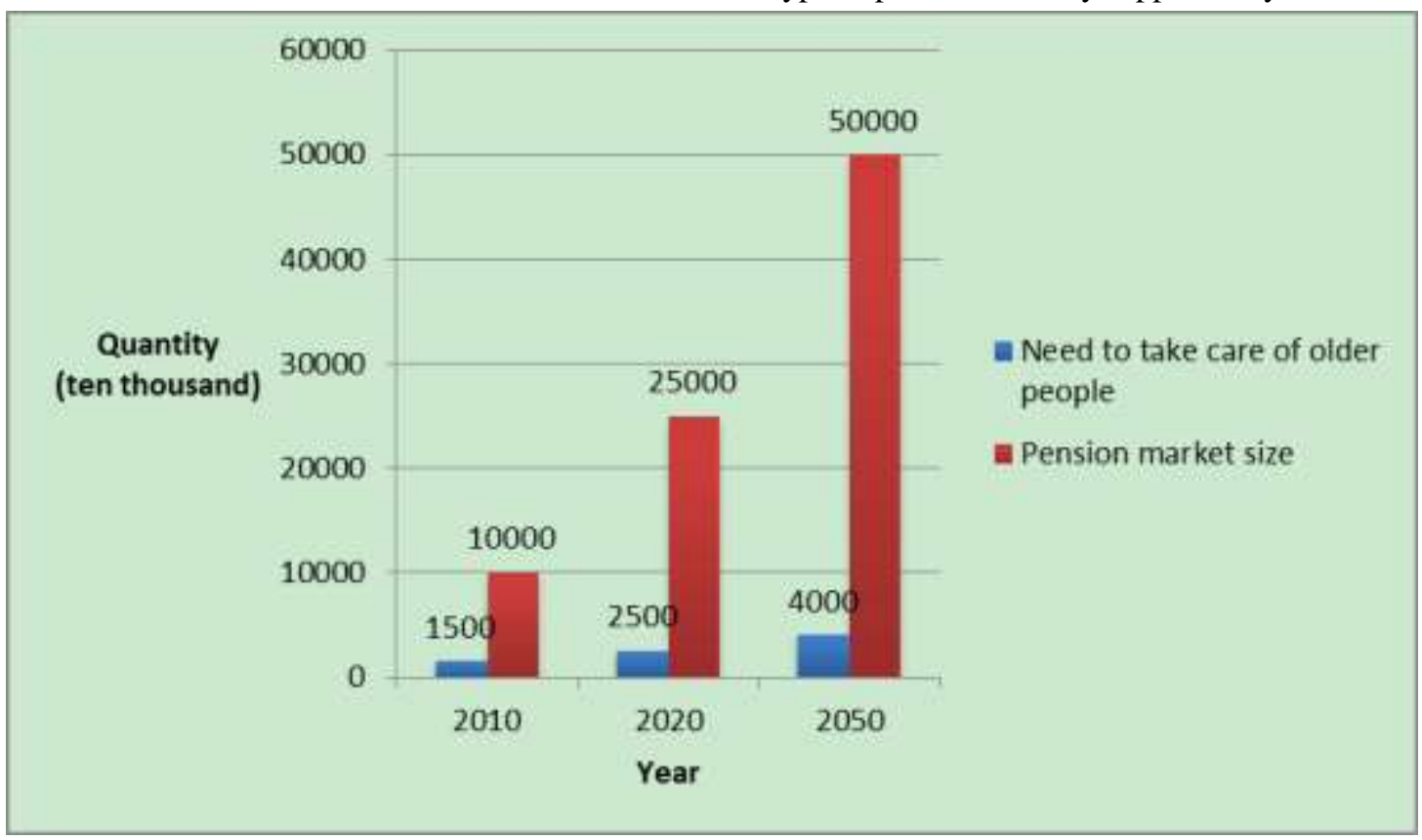

Fig. 2. Future pension market size charts.

\section{Aging Market Demand}

With the people's living standard increasing day by day, the economic conditions are increasingly affluent, the aging industry usher in new opportunities for development.
According to an interview survey, we know that the elderly are not content with eating well and have a healthy body and are eager to have a much richer later life. In addition, there are quite different concerns among the elderly at different ages about the aging industry: the elderly over 80 are 
conservative about the pension industry and focus on medical services; while younger seniors want to be in line with the times and enjoy modern scientific and technological achievements, the use of network tools to facilitate services, physical activity through the center of the elderly activities, eager to have their own generation of friends circle to avoid old age loneliness, from the heart of happiness. According to the questionnaire, $51.02 \%$ of grandchildren communicate with their grandparents frequently once or twice a quarter for even longer periods of time. $63.33 \%$ of grandchildren cannot clearly remember the important anniversaries of the elderly. Therefore, to provide the elderly with more than simply provide basic services, but also from the heart to take action, which is the pension industry has been eager to solve the problem.

Middle-aged people around the age of 50 can be regarded as potential customers in the pension industry. People in this age group have witnessed the tremendous changes in China's development and have experienced the first bitter and sweet life. Therefore, the pursuit of consumer quality and consumer experience surpasses that of the simple material needs of cheap, this is the opportunity brought by consumer upgrades to the old-age industries.

\section{THE CURRENT STATUS OF PENSION INDUSTRY}

Pension industry is not an independent industry in the traditional sense. With the increase of the wealthy class and the aging of the population and the change of the age structure of the population, the special needs of the people and the elderly who have health needs are provided with special commodities, facilities and services to meet their special needs. Relying on the first, second and traditional tertiary industries derived from special comprehensive new industries, with obvious publicity, welfare and high profitability.

\section{A. National Policy Support}

In the past ten years, the Chinese government began to attach great importance to the issue of pension and the pension industry was facing unprecedented opportunities for development. In response to the arrival of an aging society and its ever-accelerating development trend, the state has continuously introduced relevant policies to support and standardize the development of the pension industry at the policy level. As early as the 17th National Congress of the Communist Party of China (NPC) report, it has been clearly stated that "having the elderly and supporting the common people" is an important part of improving people's livelihood. Both the government and the community should actively support the exploration and innovation of the diversified urban pension model and the various problems encountered in the innovative pension model Issue, to make practical action to better meet the needs of the elderly population. In accordance with the principle of policy guidance, government support, social establishment and market promotion, the development of the pension service should give prominence to the work priorities and define the policies and measures so as to gradually establish and perfect a service system based on home-based care, community service and institutional care. The government actively supports the establishment of pension services in various ways, including public-private construction, private-sector assistance, government subsidies, and purchase services, and encourages social funds to set up pension services in the form of sole proprietorship, joint ventures, cooperation, joint ventures and share participation. We must adhere to the direction of socialization, encourage the government, society and families to participate in various forms and strive to mobilize the positive factors in all fields so as to jointly accomplish this task. On February 25, 2015, Ministry of Civil Affairs, Development and Reform Commission and other 10 ministries and commissions jointly released the Opinions on Encouraging Private Capital to participate in the Development of Pension Services, which indicates that the pension industry in our country will usher in a new phase.

\section{B. Today's Advantages}

Compared with the rapid development of the aging process, China's pension industry is still in the "initial stage", the development is relatively lagging behind. The issue of supporting the aged has become a national strategy and the state encourages the development of the six major pension industries. These include the elderly health management services, the aged care and recuperation industry, the elderly domestic service, the aged culture and education, the elderly livable service and the elderly financial wealth management. Based on national policies, combined with social surveys and market research, we found that the pension service industry has great potential as a sunrise industry. In addition to the development advantages mentioned above, such as population aging and policy support, there are the following advantages:

- The pension income level and subsidy level of the elderly in the country are continuously increasing, providing more economic support for elderly people to purchase pension services. It can be seen that the pension industry is one of the pillar industries in line with the new round of national strategy and strong demand. As the investment in pension services is intensified, the pension industry will enter a period of rapid construction in the next two years.

- Compared with other consumer groups, the elderly groups have their own characteristics due to the obvious differences in their physiological, psychological and empirical characteristics. Therefore, consumer behaviors in the elderly market also have their own characteristics, including strong selfconsumption, habitual stability and behavior Rational, the pursuit of practical convenience. These consumption characteristics of the elderly also determine the differences in the provision of end-oflife supplies and services as compared with the other, resulting in the formation of a special consumer market for the elderly.

- The elderly have less communication export. Because their children are busy with work, they have less time to communicate with the elderly and action 
inconveniences of the elderly; therefore, the elderly have a great demand for the aged service industry.

\section{Pension Industry DeVelopment Model}

\section{A. Foreign Pension Model}

Elderly community abroad is one of the earliest countries in the world to enter the era of "silver hair" - Britain. The community care model for the elderly has achieved quite good results. This model, for the aging of China, there is considerable reference. Since the 1990s, the Britain has incorporated the issue of aging into the community and adopted a model of community care for the elderly. The main contents include: First, life care (catering diet, cleaning, shopping, etc.). Life care is divided into: home services, family care, elderly apartments, and care for the elderly and other four forms. Second, material support (provision of food, installation facilities, tax relief, etc.). For example, local or volunteer organizations provide hot meals on special vehicles, install staircases, bathrooms, toilets and other handrails for them, and set up facilities such as stairways and electrical appliances and heating equipment, remodeling of kitchen and door. Third, psychological support (treatment, nursing, health care, etc.). For example, health care doctors come to the elderly to see a doctor and avoid prescription costs; health visitors come to the elderly to teach health care, such as keeping warm, preventing paralysis, nutrition and helping the elderly to prevent diseases. In addition, it also provides for the elderly to provide vision, hearing, teeth, spirit and other special services. Fourth, the overall care (to improve the living environment, to mobilize the surrounding resources to support, etc.). For example, the Britain funded the establishment of a community service center with integrated services for the elderly to provide an entertainment and social place. The elderly with limited mobility are regularly dispatched from the center by car. At the same time, in order to help the elderly to get rid of loneliness, promote mental health and appropriately increase the income of the elderly, the community provides the elderly with the best place - the elderly studio. Community care has many advantages over traditional family and oldage care homes. It combines the traditional long-term care of family and old-age homes with more humane principles and pays more attention to the psychology of the elderly and emotional care enables the elderly to live a normal life and enhance the quality of life of the elderly.

With reference to the development experience of the aged in Japan, home-based pension will remain the mainstream pension model in the future. In our opinion, the future of the home-based pension service market facing the "Internet + " pension companies will be even greater. The company providing pension services will have a larger future growing space.

\section{B. China's Pension Model}

Family pension, institutional pension and community home-based care are the three basic pension models in our country at present. Family support is the traditional model of old-age pension, nursing home retirement is a social pension model, community home-based care is a family and social care model as in "Fig. 3".

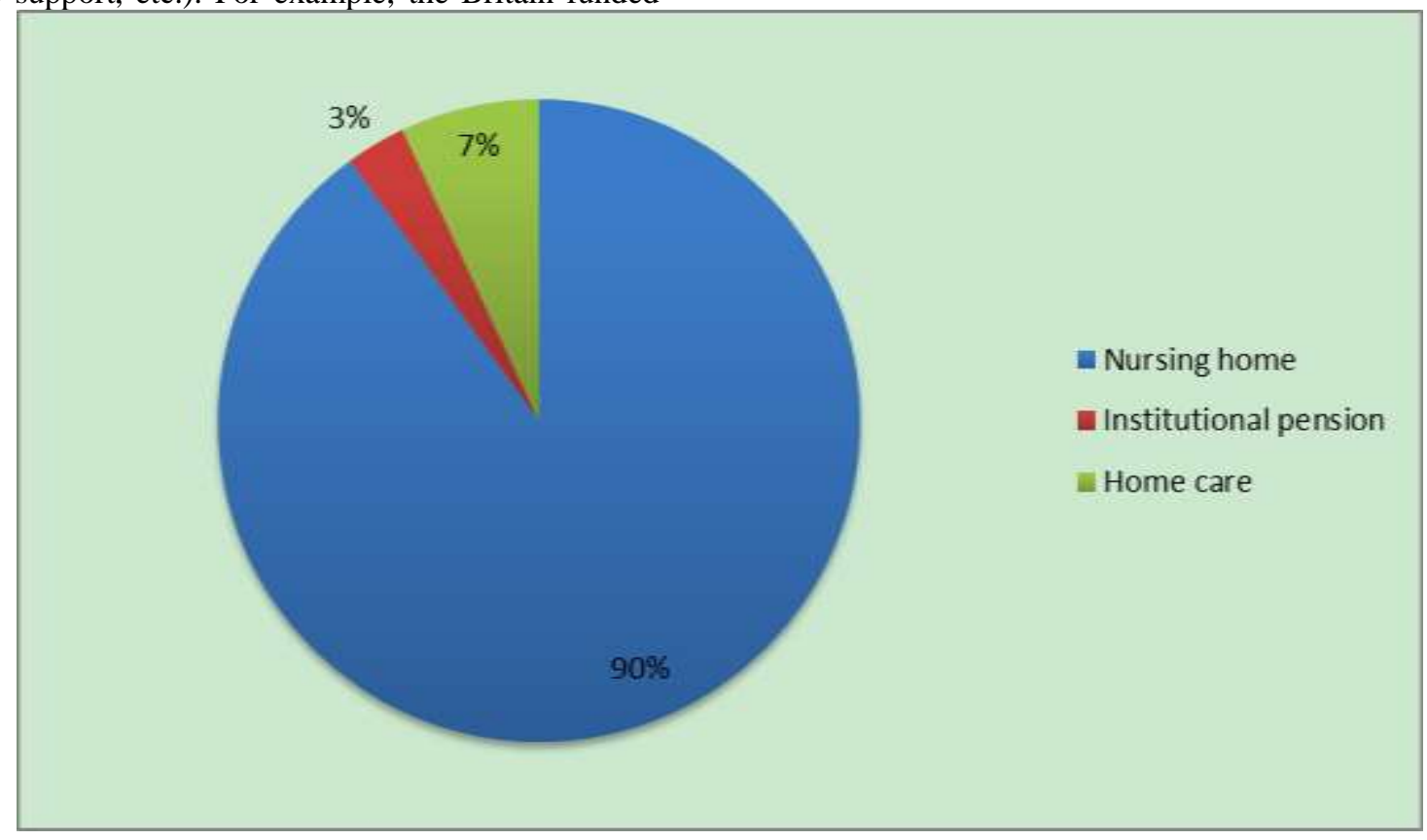

Fig. 3. Twelve five pension planning structure. 


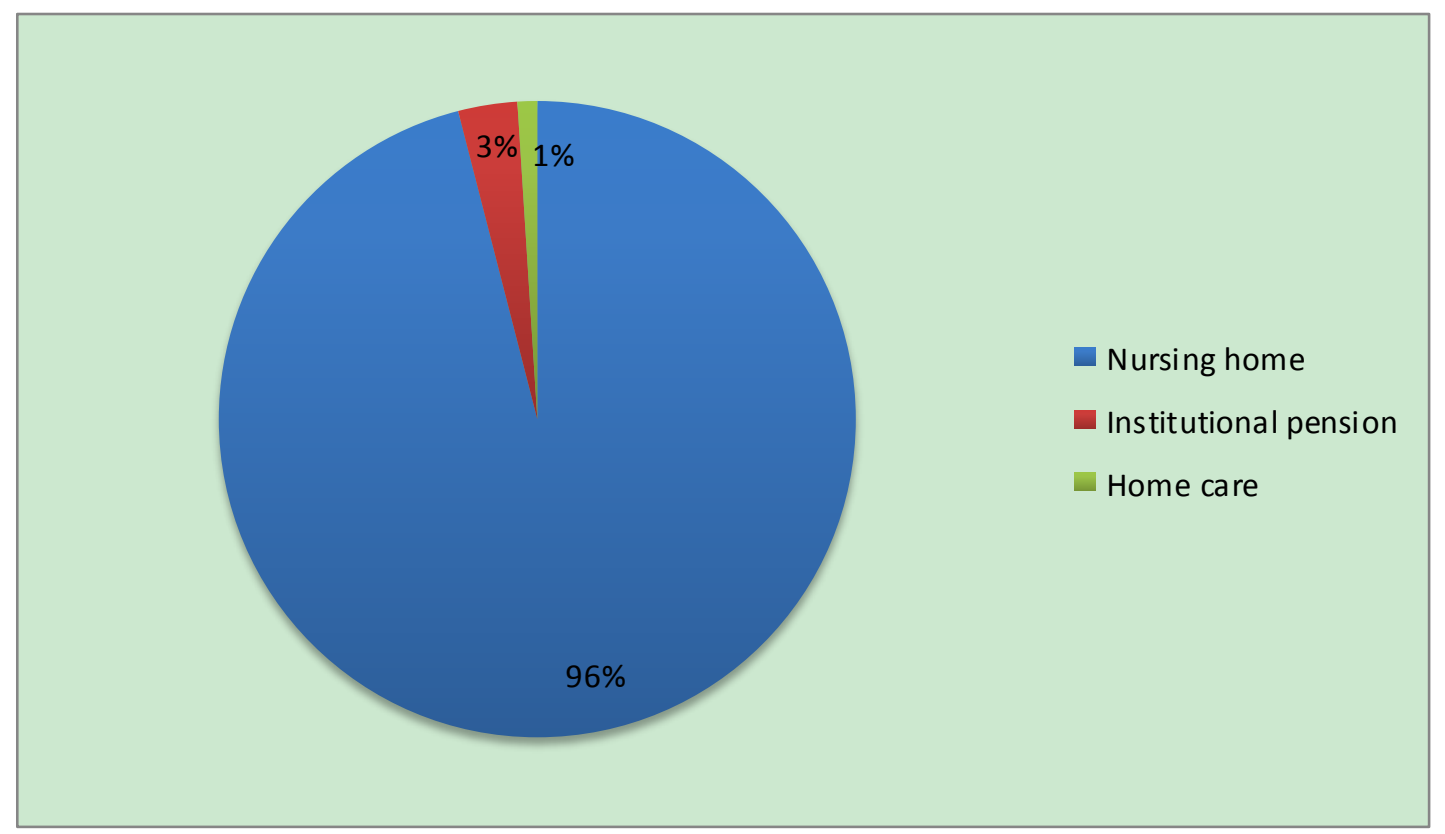

Fig. 4. Current pension structure.

As interpersonal competition intensifies in modern society as in "Fig. 4", the pace of life is accelerating and the work burden is aggravated. As a result, the cost of manpower for family retirement soars, the average family cannot afford it, and the supporters are exhausted. The increase of "4-2-1" families and empty nest families the emergence of the problem and the frailty of the family pension in the new situation show its historical limitations. Therefore, the traditional pension scheme for family retirement is bound to gradually transition to social care for the elderly with changes in family structure.

Institutional support for the aged is one of the most important pension models in our country. Formal pension institutions have strict requirements for daily management and cannot meet the needs of the elderly with diversified needs.

The basic approach to providing home-based care in the community is to establish an aged care service center in each community in the city. The elderly still live in their own home and enjoy the nutrition and medical care and psychological counseling provided by the service center. The service center sends trained aged care workers to press Appointment to the elderly at regular intervals for the elderly to provide meals, cleaning, housekeeping and other housekeeping services and accompany the elderly, listen to the elderly to tell family services. The so-called community home care is a non-walled nursing home, home care services relative to the institution of old-age pension, and more to adapt to our elderly lifestyle and psychological characteristics, to meet the psychological needs of the elderly, help them settle down old age, more in line with Chinese reality.

\section{CONCLUSION}

The process of population aging is accelerating, the pension industry continuously releases market opportunities, and the pension service industry is developing steadily in a positive and healthy manner under the promotion of a series of national policies. This paper argues that the pension industry will diversify from the real estate field and the food and health field to meet the diverse needs of the elderly. Combined with the characteristics of aging in China, in a period of time, the old-age development mode will still mainly rely on home care, and actively learn from the British pension community mode, improve pension care, home service, and psychological counseling, increase material support, and gradually transform into the community pension.

\section{REFERENCES}

[1] Qiu Juxiang. Elderly British court mode for the development of China's elderly community care. Chinese journal of modern nursing. 2010, 7 (16) : online journal

[2] Tian Xianglan. Comparative study of old-age pension industry and career - Japan's old-age pension industry and career, for example. Journal of tianjin university (social science edition), 2010, 12 (1) : 2935

[3] The People's Republic of China, the national bureau of statistics Smoke the national $1 \%$ population sample survey in 2005 main data bulletin [EB/OL]. [2006-03-16]. http://www.stats.gov.cn.

[4] li Xuebin. Our country community endowment service research review [J]. Journal of ningxia social science, 2008 (1) : 42-46.

[5] Zheng Jianjuan. Our country the status quo and development of community endowment ideas [J]. Journal of business research, 2005 (12) : 159-160.

[6] Feng yunghua. Aging industry development problems and countermeasures research in China [J]. Journal of economic study Tribune, 2011, (35). 
[7] Zhang Mengbing. China's aging industry development strategy study [J]. Science and technology entrepreneurship monthly, 2011, (03). 